E. J. Hunt, C. Zhang, N.Anzalone, and J. M. Pearce. Polymer Recycling Codes for Distributed Manufacturing with 3-D Printers, Resources, Conservation and Recycling 97, pp. 24-30 (2015). DOI: 10.1016/j.resconrec.2015.02.004

\title{
Polymer Recycling Codes for Distributed Manufacturing with 3-D Printers
}

Emily J. Hunt ${ }^{1}$, Chenlong Zhang ${ }^{1}$, Nick Anzalone ${ }^{1}$, and Joshua M. Pearce ${ }^{1,2, *}$

${ }^{1}$ Department of Materials Science \& Engineering, Michigan Technological University, Houghton, MI 49931, USA

2 Department of Electrical \& Computer Engineering, Michigan Technological University, Houghton, MI 49931, USA

*Corresponding author: Michigan Technological University, 601 M\&M Building, 1400 Townsend Drive, Houghton, MI 49931-1295 (pearce@mtu.edu) ph: 906-487-1466

\begin{abstract}
With the aggressive cost reductions for 3-D printing made available by the open-source self-replicating rapid prototypers (RepRaps) the economic advantage of custom distributed manufacturing has become substantial. In addition, the number of free designs is growing exponentially and the development and commercialization of the recyclebot (plastic extruders that fabricate 3-D printing filament from recycled or virgin materials) have greatly improved the material selection available for prosumer 3-D printer operators. These trends indicate that more individuals will manufacturer their own polymer products, however, there is a risk that an even larger fraction of polymer waste will not be recycled because it has not been coded. The current limited resin identification codes available in the U.S. similarly restricts closing the loop on less popular polymers, which could hamper the environmental impact benefits of distributed manufacturing. This paper provides a solution for this challenge by 1 ) developing a recycling code model based off of the resin identification codes developed in China that is capable of expansion as more complex 3-D printing materials are introduced, 2) creating OpenSCAD scripts based on (1) to be used to print resin identification codes into products, 3) demonstrating the use of this functionality in a selection of products and polymer materials, and 4) outlining the software and policy tools necessary to make this application possible for widespread adoption. Overall the results showed that a far larger resin code identification system can be adopted in the U.S. to expand distributed recycling of polymers and manufacturing of plastic-based 3-D printed products.
\end{abstract}

Keywords: 3-D printing; additive manufacturing; recycling codes; polymers; distributed manufacturing

\section{Introduction}

Polymer-based products have become a core part of society with population growth and technological development have resulted in the global production of plastic increasing by $500 \%$ over the last 30 years and it is expected to continue to grow to 850 million tons per year by 2050 [1-3]. In the U.S. alone growth rates are expected to be $0.9 \%$ /year for the next five years resulting in a $\$ 97.9$ billion industry [4]. Desktop three-dimensional (3-D) printing is an additive manufacturing technology that allows fabrication of complex polymer products to be moved from the factory to the home or office [5,6]. The technology is predicted to bring the next industrial revolution and is developing rapidly [7,8]. It is estimated that the global market for additive manufacturing is worth about $\$ 3$ billion and will be worth $\$ 21$ billion by 2020 [9]. Not only are the advances in proprietary printers contributing to this growth 
E. J. Hunt, C. Zhang, N.Anzalone, and J. M. Pearce. Polymer Recycling Codes for Distributed Manufacturing with 3-D Printers, Resources, Conservation and Recycling 97, pp. 24-30 (2015). DOI: 10.1016/j.resconrec.2015.02.004

[7,9], but so are advances in open-source self-replicating rapid prototypers (RepRaps) and their commercialized derivatives [10]. RepRaps are the most commonly used 3-D printers [11]. They print primarily in polylactic acid (PLA) and acrylonitrile butadiene styrene (ABS). The low capital cost of the RepRaps coupled with their ability to print complex geometries of high value products have made them an economically attractive investment for the average U.S. household already [12].

The economic advantage of distributed manufacturing increases by an additional order of magnitude with the introduction of recyclebots [13], which are waste plastic extruders that are used to produce 3D printer filament. Recyclebots of various designs are now being developed and commercially distributed allowing filament production, from either virgin or recycled material including the Lyman [14], Filastruder [15], FilaFab [16], Filabot [17], EWE [18], ExtrusionBot [19], and the Strooder [20]. This development also improves the variety of materials, with filament commercially available with the following materials: ABS, PLA, poliamide (e.g. nylon, Taulman 618), polycarbonate (PC), polyvinyl alcohol (PVA), high-density polyethylene (HDPE) [21], Laywood [22], Laybrick [23], high impact polystyrene (HIPS) [24], steel [25], aluminum [26], PEEK [27], polyphenylsulfone (PPSF or PPSU) [27], polyetherimide (PEI) [27], polyoxymethylene (POM) [28], Polykey PLA HS [29], PLA HS NX [29], Polykey PPGF [29], PPMF [29] and Polykey PA6GFV0 [29]. It appears clear that as RepRaps improve in reliability, continue to decline in cost and both the number and assumed utility of opensource designs continues growing exponentially, open-source 3-D printers will become a mass-market device for custom distributed manufacturing [12]. People want them for do-it-yourself (DIY) projects, items for use in the home, custom jewelry and accessories, or creation and prototyping of new technologies and ideas [30]. Life cycle analysis of both distributed 3-D printing [31,32] and distributed recycling $[21,33]$ indicate a significant environmental benefit over traditional manufacturing and recycling.

Unfortunately this growth in 3-D printing has a risk of creating even more unrecycled and wasted plastic than is currently created by the conventional plastic industry. Waste plastic creates a substantial environmental burden on both land [34] and water pollution [35] as plastics are slow to decompose naturally (taking from 10 to 450 years in a landfill [36]) and toxic to burn [37]. Plastic processing, use, and disposal also comprise a significant source of energy consumption as determined by a large collection of life cycle assessment (LCA) studies on plastic [38-42] and recycling [43-47].

Although both primary and secondary recycling schemes are well established and widely applied [48], in 2012, 32 million tons of plastic waste was produced in the U.S. and only $9 \%$ of that or 2.88 million tons of that were recycled [49]. Historically polymer recycling has been trending towards large-scale centralized facilities to take advantage of economies of scale in producing low-value commodities [50,51]; but this method has the challenge of collection and transportation for high volume, low weight polymers [52], which must be subsidized by higher value recycled content material such as aluminum [53]. The second reason plastics are not recycled is resin identification coding system used in the U.S. [54]. Today seven types of plastics are commonly recycled and identified with seven codes: 1) polyethylene terephthalate (PET), 2) high-density polyethylene (HDPE), 3) polyvinyl chloride (PVC), 4) low-density polyethylene (LDPE), 5) polypropylene (PP), 6) polystyrene (PS), and 7) "other", which is primarily polycarbonate (PC) and $\mathrm{ABS}$, but can also refer to mixed plastics [54]. The current recycling system is extremely limiting as there are many more commonly used polymers. Other 
E. J. Hunt, C. Zhang, N.Anzalone, and J. M. Pearce. Polymer Recycling Codes for Distributed Manufacturing with 3-D Printers, Resources, Conservation and Recycling 97, pp. 24-30 (2015). DOI: 10.1016/j.resconrec.2015.02.004

systems have adapted to materials diversity. For example, China's polymer identification system has seven different classifications of plastic, five different symbols for post-consumer paths, and 140 identification codes [55]. The U.S. system is particularly lacking when put in the context of a growing trend of distributed 3-D printing for manufacturing plastic products. There are simply not recycling codes for the majority of 3-D printing polymers in the U.S. system, while these same plastics are covered by China's system. Today, this additional plastic waste is minor, but with the growth of 3-D printing it has the potential to represent a significant environmental burden.

This paper provides a solution for this challenge by 1) developing a recycling code model based off of the resin identification codes developed in China that is capable of expansion as more complex 3-D printing materials are introduced, 2) creating OpenSCAD scripts based on (1) to be used to print resin identification codes into products voluntarily by prosumers, 3 ) demonstrating the use of this functionality in a selection of products and polymer materials, and 4) outlining the software and policy tools necessary to make this application possible for widespread adoption as distributed manufacturing with 3-D printing becomes widespread.

\section{Material and Methods}

\subsection{Proposed Voluntary Recycling Code}

A voluntary recycling code model based off of the resin identification codes developed in China uses five classifications of post-consumer plastic [55]:

1. Nonrecoverable Plastic - plastics that by law cannot be recycled in anyway.

2. Recoverable Plastic - plastics that can be recycled.

3. Rerecycled Plastic - recycled plastic that is being reused to make a product.

4. Reworked Plastic - waste plastic from manufacturing that can be reworked into a product.

5. Repeatable Use Plastic - plastic that can be used over and over again without needing to be thrown out or recycled

Each classification has its own symbol and, with the exception of the Nonrecoverable Plastic symbol, the identification number of the main plastic is placed in the center of that symbol. A simple description of the function or specific property of the material is placed beside the symbol (e.g. biodegradable or high impedance). For further identification the abbreviation of the main polymer is placed underneath the symbol in ' $><$ '. If the plastic is a monocomponent plastic just the abbreviation of the polymer is needed, e.g. $>$ PLA $<$ (see Appendix 1 for all abbreviations and resin code numbers). Note that in Appendix 1, China's model was used unless there were already standard U.S. abbreviations in wide use. However, some 3-D printer filaments are made of mixed polymers or have thermoplastics with functional additives. In these cases further identification is needed. If the plastic is a polymer mixture then all that is needed is the abbreviations of each polymer in the plastic with '+' in between them, e.g.: $>$ PLA+ABS $<$. Other added materials have four different categories: filler/reinforced material, plasticizer (Z), fire retardant (FR), and recycled/reworked plastics (R). Fillers or reinforced materials are noted with a dash followed by the abbreviation of the filler material next to the weight percent of the object that it is, ex PET with 30\% carbon black $>$ PET-CB30<. If there is more than one filler material then the fillers are put in parenthesis still following a dash and with their weight percentages 
E. J. Hunt, C. Zhang, N.Anzalone, and J. M. Pearce. Polymer Recycling Codes for Distributed Manufacturing with 3-D Printers, Resources, Conservation and Recycling 97, pp. 24-30 (2015). DOI: 10.1016/j.resconrec.2015.02.004

but a plus separates the fillers, ex PET with 25\% glass fibers and 15\% carbon black >PET$(\mathrm{GF} 25+\mathrm{CB} 15)<$. Plasticizers are noted with a 'Z' on the outside of the parenthesis that contain the plasticizer abbreviation. For example, PVC with DPB as a plasticizer $>$ PVC-Z(DPB) $<$. The ' $Z$ ' is used instead of a ' $\mathrm{P}$ ' so as to not cause confusion because $\mathrm{P}$ is in a large number of the polymer abbreviations in the code system. Fire retardants follow the same format. For the reworked or rerecycled plastic the polymer is in front of parenthesis containing ' $\mathrm{R}$ ' with the weight percent following the parenthesis, ex $\mathrm{PP}$ with $30 \%$ recycled $\mathrm{PP}>\mathrm{PP}-\mathrm{PP}(\mathrm{R}) 30<$. This is necessary knowledge of the other added materials may preclude specific applications (e.g. the use of phthalates as a plasticizer in children's toys).

\subsection{OpenSCAD Recycling Symbol Script}

In order to make this polymer code system accessible to people with 3-D printers, designs were developed using OpenSCAD [56], a script based CAD package. It allows the user to input the recycling symbol along with the abbreviations and their various identifiers. This code is open-source and available for anyone to incorporate into their 3-D model. The code was designed to be implemented in any other OpenSCAD designs using the include or use commands. Users place the .scad file and its dependencies in the same directory of their design. This allows the user to call upon the Recycling Symbol module and alter the variables, which determine the recycling symbol, the numerical code, the symbol of the plastic, and all the dimensions of the recycling symbol with one line of code. The dimensions that can be altered are the length, width and thickness of the overall symbol, and the width, length and thickness of the arrows for which the symbol is composed. For example, the code used to make the symbol in Figure 1 is:

Recycling_Symbol(Symbol $=1$,Numerical_Code $=$ "108", Plastic_Symbol $=$ "PS-HI", Length $=30$, Width $=23$, Thickness $=3$, Arrow_Width $=3$, Arrow_Head_Width $=5$, Arrow_Head_Length $=4$ );

The symbols that where modeled where based on [55], with a total of 5 symbols that the user can format for their design: recoverable, non recoverable, re-recycled, reworked and repeatable plastic symbols.

Currently the guidelines for use of the code suggest that the symbol be unobtrusive and inconspicuous so the consumer does not take recycling into account when buying a product [57]. Because this code is customizable the symbol can be made any size, depending on the printer resolution, and be placed anywhere on the item.

\subsection{Code Incorporation Tests}

In order to test the viability of the method provided in the previous two subsections various household objects were printed using a representative selection of open-source 3-D printers: Trinity One [58] with an all metal extruder for high temperature plastic (HIPS and PC), a Lulzbot Taz for printing in flexible polymers like thermoplastic elastomers (TPE), a MOST Delta RepRap [59] for PLA, ABS, and recycled ocean plastic (primarily HDPE) provided by the Plastic Bank [60]. OpenSCAD was used to create the 3-D model with the recycling symbol located in a convenient location of six household objects:

1) wrench was printed with HIPS,

2) toothpaste tube squeezer was printed using PC,

3) a ball was printed in TPE, 
E. J. Hunt, C. Zhang, N.Anzalone, and J. M. Pearce. Polymer Recycling Codes for Distributed Manufacturing with 3-D Printers, Resources, Conservation and Recycling 97, pp. 24-30 (2015). DOI: 10.1016/j.resconrec.2015.02.004

4) a drill bit handle was printed in ABS,

5) a pencil cup, was printed in PLA,

6) an earphone holder printed in HDPE.

\section{Results}

Overall the quality of the test prints was very good, with some variation due to material, printer and the object being printed. First, for objects whose strength matters more than aesthetic the symbol can be printed right on the front surface. To demonstrate this a functional wrench was printed with highimpact polystyrene as shown in Figure 1. For all the of the resultant 3-D prints the inset shows the CAD design to demonstrate the printing fidelity even in low-cost 3-D printer designs. The recycling symbol was embedded deep enough to be easily seen, but not too deep to compromise the integrity of the wrench. The prosumer can also reduce the depth of embedding to make the recycling symbol only visible at certain angles of observation as shown in Figure 2 for the polycarbonate toothpaste tube squeezer with the symbol printed on the flat face. The simple embedding approach can also be used for flexible objects like the bouncy ball shown in Figure 3, while still maintaining their function.

For objects where the aesthetic properties of the object are more important it is possible to hide the recycling symbol until it is necessary to recycle the object. Two approaches were demonstrated here.

First, a drill bit handle was printed in ABS, with no visible recycling symbol on the exterior (such handles are popular in the 3-D printing community to ream out holes in RepRap part prints). The recycling symbol is in the center of the handle so that for about 50 layers only the symbol and the wall of the handle are present. Thus, when the handle is ready to be recycled it can be cracked open (as shown in Figure 4) and the recycling symbol becomes clearly visible on the inside regardless of the location of the crack. This type of recycling symbol embedding - where the recycling symbol can become an integral (and potentially mechanically necessary) component of the part is difficult to impossible with traditional subtractive manufacturing techniques.

Second, the optical properties of the printing materials can be used to hide the recycling symbol in the object. This is demonstrated with a pencil cup (Figure 5) printed in polylactic acid (PLA), which is currently the most popular prosumer 3-D printing material. The recycling symbol is embedded into the bottom of the cup so it is only visible when lifted to a light (Figure 5 left inset). This effect was created by fabricating the cup as a solid object, with the inside filled in, and the recycle symbol is subtracted from the cup starting two layers from the bottom. Then using the 'Spiralize' settings in Cura the solid cup is turned into a hollow cup with the symbol cut out of a few layers in the cup bottom.

Finally, an earphone holder printed in "Social Plastic" recovered from a beach and provided by the Plastic Bank is shown in Figure 6 (inset left). Plastic Bank is a social enterprise with the goal of increasing global demand for their socially-responsible or social plastic in eco-friendly products. Consumers that use (and prosumers that make) such eco-friendly products may want to show off their eco-friendliness with more apparent recycling symbols. So, for example, in Figure 6, the recycling symbol is printed to be embossed in the center of the flat face and printed in the natural ocean plastic color. Because all of these prints are used with only one plastic only the number is needed if there is not enough space for notation below the symbol. 
E. J. Hunt, C. Zhang, N.Anzalone, and J. M. Pearce. Polymer Recycling Codes for Distributed Manufacturing with 3-D Printers, Resources, Conservation and Recycling 97, pp. 24-30 (2015). DOI: 10.1016/j.resconrec.2015.02.004

\section{Discussion}

While a significantly broader resin code identification system has the potential to revolutionize recycling in the U.S., due to current policies and institutional structures within ASTM through the D20.95.01 SPI Resin Code Section, such a system is unlikely to be accepted in the near future [61]. Part of this is simply inertia, as the ASTM standards are determined by consensus of all the members of the task group, which is made up of volunteer stake holders. Consider the only recent change made to the U.S. code is to change the symbol from chasing arrows (denoting recycling) to a simple equilateral triangle, which was made to avoid 'consumer confusion' as recycling of all the recyclable plastics is not available in all municipalities. For those concerned about fostering sustainable behavior in consumers this would be appear to be step backward [62]. Similarly, pro-recycling laws can have unintended consequences. For example, California's Electronic Waste Recycling Act of 2003, which levies different fees on electronic devices or screens depending on the recyclability and size of the object [63], provides a disincentive to firms producing any polymer without a code to adopt one. The ASTM task group is discussing adding extra identification by adding extensions to the numbers, to help recyclers better identify what is in the plastic. However, the change is unlikely to take place as some members feel adding any additional information to the existing U.S. code is unnecessary because the main six resins account for $3 / 4$ of plastic waste $[57,64]$ and such a small percentage of that is currently recycled. This thinking is predicated on a centralized recycling model, which currently dominates polymer recycling in the U.S. However, with the growth of distributed 3-D printing for manufacturing, in the future the plastic waste produced will no longer necessarily continue to be limited these six resins as the new developed filaments range widely in materials. The number of registered 3D-printers to 3D Hubs grew 2,100\% from last year alone [65]. This growth coupled with the decrease in cost per consumer objects is dropping by as much as $35 \%$ in some categories shows the growth is occurring now [65].

This distributed production of more complex materials is complimented by the development of recyclebots, including the proprietary commercial, open-source and DIY varieties. Because the recycling as well as manufacturing can now be located in the home, at a local business, or community center, the prosumer needs to know what they can use and what is not compatible with their machines. Currently due to the relatively low-reliability of the 3-D printers (some studies estimate $20 \%$ failure [12]), prints do not always work the first time, and thus there is a large source of reusable scrap plastic associated with most FFF 3-D printers. Being able to reuse these failed prints or use waste plastic to make additional filament is very cost effective for the prosumer [13]. There are organizations such as The Plastic Bank [66], Ethical Filament Foundation [67], and the Perpetual Plastics Project [68] that are dedicated to waste plastic recycling for 3-D recycled filament. Recycling has been proven to have lower environmental impact than incineration and landfilling, and while various methods have varying results increased use of recycled plastic is expected impact the environment positively [69-71]. In addition, distributed recycling has been shown to be able to reduce the environmental impact of plastic from conventional recycling [31]. Thus, the easier it is to identify and recycle plastics using these distributed methods, the better it will be for the environment.

While this code system is a significant improvement over the current resin identification system, there is room for even greater improvement. Incorporating the symbol directly into the open-source slicer 
E. J. Hunt, C. Zhang, N.Anzalone, and J. M. Pearce. Polymer Recycling Codes for Distributed Manufacturing with 3-D Printers, Resources, Conservation and Recycling 97, pp. 24-30 (2015). DOI: 10.1016/j.resconrec.2015.02.004

programs like Cura [72], Slic3r [73], and Skeinforge [74], will increase the ease the symbol can be set into 3-D models. Instead of creating the model with the symbol in it, the symbol can be generated while slicing the model into g-code, all that is needed are variables to indicate the symbol, polymer, and any extra substances the filament contains. Building off of the work here as shown in Figure 4, it would be possible to make the infill be the recycling symbol itself. A few widely used plastics could have a preset and the prosumer could create their own saved symbol for plastics they use often. These presets could be identified by a quick response $(\mathrm{QR})$ code on the packages of new filament so the prosumer could avoid inputting them manually. Once the variables or preset symbols are selected all the user would need to do is select whether the symbol should be on the outside or inside, if outside then if it is to be raised or indented, how far it should be raised or indented, what size, and where on the model it should be placed. This can all be done with the current code manually in OpenSCAD, before the STL is created, which is acceptable for designers, but not everyday prosumers.

Future work is needed to adapt some of the other functions of the Chinese resin identification code to the system provided here is the functions of the various plastics (e.g. anti-bacterial, high impedance, bio-degradable, etc.). In order for this to be integrated into the symbol a code must be created to identify the function(s) of the plastic and unfortunately the Chinese system is not differentiated highly enough for this application now. Printing out all of the words, especially if the polymer has multiple functions, would make the words hard to read. If the symbol is smaller then the words would be indistinguishable, even with high-resolution printers. A simple letter, number, or abbreviation code would solve this issue, just like the polymer have their own specific abbreviations as shown in Appendix 1. This extra feature to the symbol would also help prosumers with a specific purpose for their products to find a specific plastic to re-use or see what can not be used.

The voluntary recycling protocols developed here have become more relevant to future recycling policy due in part to China's application of the Green Fence Policy established in February 2013. China imports about $70 \%$ of the worlds 12 million tonnes of plastic waste every year [75]. The Green Fence Policy restricts the amount of contaminant in waste bales to $1.5 \%$ or lower, which resulted in the rejection of over 800,000 tonnes of recyclables or scrap [76]. This change raised the cost of recycling for U.S. companies and while many companies supported this ecological policy shift, many simply shifted waste exports to other countries such as Turkey or Vietnam on economic grounds [77]. This policy change shocked the industry and showed that the main issue with North American recycling is the need for better quality control [78].

The recycling code system developed here is a voluntary system for which prosumers will implement for their own benefit. Thus, it avoids the challenges associated with exporting waste plastic internationally. Although, the estimated sales of personal 3D printers from 2007 to 2011 was $346 \%$ each year [9], today the total prosumer plastic waste is still a tiny fraction of a percent of the U.S. whole. Until distributed production and recycling have become the norm, improvements are needed in the U.S. system. In order for the sum total of U.S. recyclable plastic waste to be recycled, particularly in the short term, the U.S. resin code must be expanded and adopted by the plastic industry as a whole. For this to happen legislation is needed to make it mandatory at the national level, as unlike the 
E. J. Hunt, C. Zhang, N.Anzalone, and J. M. Pearce. Polymer Recycling Codes for Distributed Manufacturing with 3-D Printers, Resources, Conservation and Recycling 97, pp. 24-30 (2015). DOI: 10.1016/j.resconrec.2015.02.004

prosumer-based system investigated here (where recycling by being in line with the prosumer's economic interest), the centralized system externalizes costs to such an extent that the economic incentive is lost. Currently, the recycling code in the U.S. is changed and regulated by the ASTM, a non-profit private organization that focuses on developing international standards [78]. In order to expedite this change the responsibilities of expanding the codes and regulations on recycling should be investigated by government at the national level, similar to the policy implementations in China [79].

By enabling the government to regulate recycling codes, the market can operate more efficiently as full costs will be accounted for in transactions, and economic incentives can be aligned with the benefits to the environment and the rest of society.

\section{Conclusions}

This study has developed a recycling code model capable of expansion as more complex 3-D printing materials are developed. In addition, this study developed and tested the OpenSCAD scripts necessary to implement the system at the prosumer level as recycling symbols are printed into products. The use of this functionality was demonstrated in a wide selection of products, polymer materials and mechanisms to be suitable for most applications. Future work outlining the software changes to make this system widespread by lateral scaling was provided. In addition, to help both this distributed recycling system and the conventional centralized recycling paradigm, policy suggestions were outlined to align the societal and environmental outcomes with economic incentives for corporations. Overall the results showed that a far larger resin code identification system can be adopted in the U.S. to expand distributed recycling of polymers and manufacturing of plastic-based 3-D printed products.

\section{Acknowledgements}

The authors would like to acknowledge support for this study from Tech for Trade, The Plastic Bank and the Link Research Internship.

\section{References}

1. Lebreton LC-M, Greer SD, Borrero JC. Numerical modeling of floating debris in the world's oceans. Marine Pollution Bulletin; 2012:64(3):653-61.

2. Lotfi A. Plastic/Polymer Recycling; 1997. (accessed Sept 11, 2014) Available from: http://www.lotfi.net/recycle/plastic.html

3. Shen L, Haufe J, Patel MK. Product overview and market projection of emerging bio-based plastics. Copernicus Institute for Sustainable Development and Innovation-Utrecht University; 2009.

4. Krompton J. IBISWorld Industry Report 32521: Plastic and Resin Manufacturing in the US; 2014.

5. Lipson H, Kurman M. Fabricated: The New World of 3D Printing. Wiley, Indianapolis, In.; 2013.

6. Gershenfeld N. Fab: The Coming Revolution on Your Desktop - from Personal Computers to Personal Fabrication, Basic Books, New York; 2005. 
E. J. Hunt, C. Zhang, N.Anzalone, and J. M. Pearce. Polymer Recycling Codes for Distributed Manufacturing with 3-D Printers, Resources, Conservation and Recycling 97, pp. 24-30 (2015). DOI: 10.1016/j.resconrec.2015.02.004

7. The Economist. A third industrial revolution: Special report: Manufacturing and innovation, The Economist; 2012.

8. Corney J. The next and last industrial revolution?, Assembly Automation 2005; 25(4):257.

9. Wohlers Associates. Wohlers Report 2014, Wohlers Associates; 2014.

10. Jones R, Haufe P, Sells E. RepRap - the Replicating Rapid Prototyper, Robotica 2011; 29(1):177191.

11. Moilanen J, Vadén, T. Manufacturing in motion: first survey on the 3D printing community, Statistical Studies of Peer Production. (see also: http://surveys.peerproduction.net/2012/05/manufacturing-in-motion ).

12. Wittbrodt BT, Glover AG, Laureto J, Anzalone GC, Oppliger D, Irwin JL, Pearce JM. Life-cycle economic analysis of distributed manufacturing with open-source 3-D printers, Mechatronics 2013; 23:713-726.

13. Baechler C, DeVuono M, Pearce JM. Distributed recycling of waste polymer into reprap feedstock, Rapid Protyping Journal 2013;19(2):118-125.

14. Lyman H. Lyman Filament Extruder. 2012. (accessed Sept 11, 2014) Available from: http://www.thingiverse.com/thing:30642

15. Filastruder. 2014. (accessed July 10, 2014) Available from: http://www.filastruder.com/

16. FilaFab. 2014. (accessed July 10, 2014) Available from: http://www.filafab.co.uk/

17. Filabot. 2014. (accessed July 10, 2014) Available from: http://www.filabot.com/

18. EWE Industries. 2014. (accessed July 10, 2014) Available from: http://www.eweindustries.com/

19. ExtrusionBot. 2014. (accessed July 10, 2014) Available from: http://www.extrusionbot.com/

20. Strooder. 2014. (accessed July 10, 2014) Available from:

http://www.omnidynamics.co.uk/shop/strooder

21. Kreiger MA, Mulder ML, Glover AG, Pearce JM, Life Cycle Analysis of Distributed Recycling of Post-consumer High Density Polyethylene for 3-D Printing Filament, Journal of Cleaner Production 2014;70:90-96.

22. Walters R. Laywood filament lets you 3D print with wood. 2014. (accessed July 10, 2014) Available from: http:/www.geek.com/news/laywood-filaments-lets-you-3d-print-with-wood-1517745/ 
E. J. Hunt, C. Zhang, N.Anzalone, and J. M. Pearce. Polymer Recycling Codes for Distributed Manufacturing with 3-D Printers, Resources, Conservation and Recycling 97, pp. 24-30 (2015). DOI: 10.1016/j.resconrec.2015.02.004

23. 3ders.org. 2014. (accessed July 10, 2014) Available from: http://www.3ders.org/articles/20130527laybrick-a-new-rough-3d-printer-filament-near-zero-warp.html

24. 3mm HIPS, Formfutura. 2014. (accessed July 10, 2014) Available from:

http://www.formfutura.com/3mm-hips.html?source=facebook (accessed July 15, 2014).

25. Anzalone GC, Zhang C, Wijnen B, Sanders PG, Pearce JM, A Low-Cost Open-Source Metal 3-D Printer, IEEE Access 2013;1:803-810.

26. Haselhuhn AS, Gooding EJ, Glover AG, Anzalone GC, Wijnen B, Sanders PG, Pearce JM. Substrate Release Mechanisms for Gas Metal Arc Weld 3-D Aluminum Metal Printing, 3D Printing and Additive Manufacturing 2014; 1(4): 204-209.

27. Arevo. 2014. (accessed July 10, 2014) Available from: http://www.arevolabs.com/

28. Lock T. Think3dPrint3d: 3D printing with Acetal Filament. 2014. (accessed July 15, 2014) Available from: http://blog.think3dprint3d.com/2013/09/3d-printing-with-acetal-filament.html

29. Sher D. Keytech Wants You to 3D Print Better, 3D Printing Industry. 2014. (accessed September 11, 2014). Available from: http://3dprintingindustry.com/2014/09/10/keytech-wants-3d-print-betterprototypes-new-filament-range/

30. McCue T. 3D Printing in the Home: 1 In 3 Americans Ready For 3D Printer, Forbes. 2014. (accessed July 9, 2014). Available from: http://www.forbes.com/sites/tjmccue/2014/03/19/3d-printingin-the-home-1-in-3-americans-ready-for-3d-printer/

31. Kreiger M, Pearce JM. Environmental Life Cycle Analysis of Distributed Three-Dimensional Printing and Conventional Manufacturing of Polymer Products, ACS Sustainable Chem. Eng. 2013;1: 1511-1519.

32. Kreiger MA, Pearce JM. Environmental Impacts of Distributed Manufacturing from 3-D Printing of Polymer Components and Products, MRS Online Proceedings 2013; 1492: mrsf12-1492g01-02.

33. Kreiger M, Anzalone GC, Mulder ML, Glover A, Pearce JM. Distributed Recycling of PostConsumer Plastic Waste in Rural Areas. MRS Online Proceedings Library 2013; 1492: mrsf12-1492g04-06.

34. Rees JF. The fate of carbon compounds in the landfill disposal of organic matter. Journal of Chemical Technology and Biotechnology 1980;30(1):161-75.

35. Derraik JGB. The pollution of the marine environment by plastic debris: a review. Marine Pollution Bulletin 2002;44:842-52. 
E. J. Hunt, C. Zhang, N.Anzalone, and J. M. Pearce. Polymer Recycling Codes for Distributed Manufacturing with 3-D Printers, Resources, Conservation and Recycling 97, pp. 24-30 (2015). DOI: 10.1016/j.resconrec.2015.02.004

36. U.S. National Park Service: Mote Marine Lab. Time it takes for garbage to decompose in the environment. (accessed September 11, 2014) Available from:

http://des.nh.gov/organization/divisions/water/wmb/coastal/trash/documents/marine debris.pdf

37. Lewis R, Sullivan JB. Toxic hazards of plastic manufacturing. Hazardous Materials Toxicology:

Clinical Principles of Environmental Health. Baltimore: Williams \& Wilkins; 1992. p. 505-15.

38. Björklund A. Recycling revisited - life cycle comparisons of global warming impact and total energy use of waste management strategies. Resources, Conservation and Recycling 2005;44(4):30917.

39. Rydberg T. Cascade accounting in life cycle assessment applied to polymer recycling. Polymer Recycling (UK) 1995;1:233-41.

40. Song HS, Hyun JC. A study on the comparison of the various waste management scenarios for PET bottles using the life-cycle assessment (LCA) methodology. Resources, Conservation and Recycling $1999 ; 27: 267-84$.

41. Arena U, Mastellone ML, Perugini F. Life Cycle assessment of a plastic packaging recycling system. The International Journal of Life Cycle Assessment 2003;8(2):92-8.

42. Reich MC. Economic assessment of municipal waste management systems - case studies using a combination of life cycle assessment (LCA) and life cycle costing (LCC). Journal of Cleaner Production; 2005;13(3):253-63.

43. Craighill AL, Powell JC. Lifecycle assessment and economic evaluation of recycling: a case study. Resources, Conservation and Recycling 1994;17:75-96.

44. Perugini F, Mastellone ML, Arena U. A Life Cycle Assessment of Mechanical and Feedstock Recycling Options for Management of Plastic Packaging Wastes. Environmental Progress 2005;24:137-54.

45. Powell JC. Lifecycle assessment and economic valuation of recycling. J. of Environmental Planning and Management 1996;39:97-112. 
E. J. Hunt, C. Zhang, N.Anzalone, and J. M. Pearce. Polymer Recycling Codes for Distributed Manufacturing with 3-D Printers, Resources, Conservation and Recycling 97, pp. 24-30 (2015). DOI: 10.1016/j.resconrec.2015.02.004

46. Ross S, Evans D. The environmental effect of reusing and recycling a plastic-based packaging system. J. of Cleaner Production 2003;11(5):561-71.

47. Subramanian PM. Plastics recycling and waste management in the US. Conservation and Recycling. Resources, Conservation and Recycling 2000;28(3-4):253-63.

48. Al-Salem, S.M., Lettieri, P., Baeyens, J.Recycling and recovery routes of plastic solid waste (PSW): A review. Waste Management 2009; 29:2625-2643.

49. U.S. EPA, Plastics, Common Wastes \& Materials, 2014. (accessed September 11, 2014) Available from: http://www.epa.gov/osw/conserve/materials/plastics.htm

50. Missouri Department of Natural Resources. Recycling Economics: Higher Costs Are An Illusion. (accessed July 15, 2014) Available from: http://www.dnr.mo.gov/env/swmp/pubs-reports/rececon.htm

51. Redd A. Regionalization brings economies of scale to east coast. World Wastes 1993;36:40-5.

52. Themelis NJ, Castaldi MJ, Bhatti J, Arsova L. Energy and Economic Value of Non-recycled Plastics (NRP) and Municipal Solid Wastes (MSW) that are Currently Landfilled in the Fifty States. New York, NY: Columbia University;2011.

53. Hood J. How green was my balance sheet. Policy Review 1995;74.

54. D20 Committee, Practice for Coding Plastic Manufactured Articles for Resin Identification, ASTM International, 2013. (accessed July 15, 2014) Available from: http://enterprise.astm.org/filtrexx40.cgi? +REDLINE_PAGES/D7611D7611M.htm .

55. Standardization Administration of the People's Republic of China (SAC) GB16288, 2008. Marking of plastics products. Chinese Standard Publishing House, Beijing; 2008.

56. OpenSCAD, 2014. (accessed July 15, 2014) Available from: http://openscad.org

57. SPI: The Platics Industry Trade Association, SPI Resin Identification Code: Guide to Correct Use, 2014.(accessed July 15, 2014) Available from: 
E. J. Hunt, C. Zhang, N.Anzalone, and J. M. Pearce. Polymer Recycling Codes for Distributed Manufacturing with 3-D Printers, Resources, Conservation and Recycling 97, pp. 24-30 (2015). DOI: 10.1016/j.resconrec.2015.02.004

http://www.plasticsindustry.org/AboutPlastics/content.cfm?ItemNumber=823\&navItemNumber=1125

58. Trinity Labs, 3D Printer. 2014. (accessed July 15, 2014) Available from:

http://www.3dprinter.net/directory/personal-3d-printers/trinity-labs

59. Michigan Tech's Open Sustainable Technology Lab, Delta Build Overview: MOST, 2014. (accessed August 4, 2014) Available from: http://www.appropedia.org/Delta Build Overview:MOST

60. Plastic Bank. (2014). Our Story. (accessed August 4, 2014) Available from:

http://plasticbank.org/our-story/

61. Pecorini T. Chair D20.95.01 task group, personal communication May-June, 2014.

62. McKenzie-Mohr D. Fostering sustainable behavior: An introduction to community-based social marketing. New society publishers; 2013.

63. California State Board of Equalization, California Electronic Waste Recycling Act of 2003, (2004), (accessed July 24, 2014) Available from: http://www.boe.ca.gov/pdf/pub13.pdf

64. Spevacek JA, It's the Rheo Thing: Still Proposing Changes to the Resin Identification Codes, 2014. (accessed July 24, 2014) Available from: http://www.rheothing.com/2014/01/still-proposing-changesto-resin.html

65. Sher D. New 3D Hubs Trend Report, 3D Printing Industry. 2014. (accessed August 12, 2014). Available from: http://3dprintingindustry.com/2014/08/12/new-3d-hubs-trend-report-shows-distributedmanufacturing-evolving-rapidly/

66. The Plastic Bank. Eco-Friendly Social Impact Social Plastic. Triple Bottom Line Social Enterprise Reducing Poverty \& Plastic Pollution. The Plastic Bank, 2014. (accessed August 5, 2014) Available from: http://plasticbank.org/

67. Ethical Filament Foundation, 2014. (accessed August 5, 2014) Available from: http://www.ethicalfilament.org/

68. Project, Perpetual Plastic Project. 2014. (accessed August 5, 2014) Available from: http://www.perpetualplasticproject.com/

69. Rajendran S, Scelsi L, Hodzic A, Soutis C, Al-Maadeed MA, Environmental impact assessment of composites containing recycled plastics, Resources, Conservation and Recycling 2012; 60:131-139.

70. Björklund A, Finnveden G. Recycling revisited — life cycle comparisons of global warming impact and total energy use of waste management strategies, Resources, Conservation and Recycling 2005; 44:309-317.

71. Chilton T, Burnley S, Nesaratnam S. A life cycle assessment of the closed-loop recycling and 
E. J. Hunt, C. Zhang, N.Anzalone, and J. M. Pearce. Polymer Recycling Codes for Distributed Manufacturing with 3-D Printers, Resources, Conservation and Recycling 97, pp. 24-30 (2015). DOI: 10.1016/j.resconrec.2015.02.004

thermal recovery of post-consumer PET, Resources, Conservation and Recycling 2010; 54:1241-1249.

72. Cura - User manual, Ultimaker, 2013. (accessed December 19, 2013)

http://blog.ultimaker.com/cura-user-manual/

73. Slic3r - G-Code Generator for 3D Printers, 2014. (accessed September 12, 2014) Available from: http://slic3r.org/

74. Skeinforge - Wiki, 2012. (accessed July 22, 2014) Available from: http://fabmetheus.crsndoo.com/wiki/index.php/Skeinforge

75. Taylor B. Clearing the Fence, Recycling Today 2014. (accessed July 25, 2014) Available from: http://www.recyclingtoday.com/rtge0114-operation-green-fence.aspx

76. K. Earley, Could China's "green fence" prompt a global recycling innovation?, The Guardian. 2013.(accessed July 10, 2014) Available from: http://www.theguardian.com/sustainable-business/chinagreen-fence-global-recycling-innovation .

77. Margolis J. China's "Green Fence" is cleaning up America's dirty recycling, Public Radio International 2014. (accessed July 10, 2014) Available from: http://www.pri.org/stories/2014-0218/chinas-green-fence-cleaning-americas-dirty-recycling

78. ASTM International, 2014. (accessed July 25, 2014) Available from: http://www.astm.org/

79. E.C. Director, Environmental, G.A.T. Pak, Opportunity Awaits on the Other Side of China's Green Fence, Environmental Management \& Sustainability News. Environmental Reader 2014. (accessed July 22, 2014)Available from: http://www.environmentalleader.com/2014/04/21/opportunity-awaitson-the-other-side-of-chinas-green-fence/

\section{Figure Captions}

Figure 1. Functional wench printed with high-impact polystyrene. Inset: OpenSCAD rendering of design.
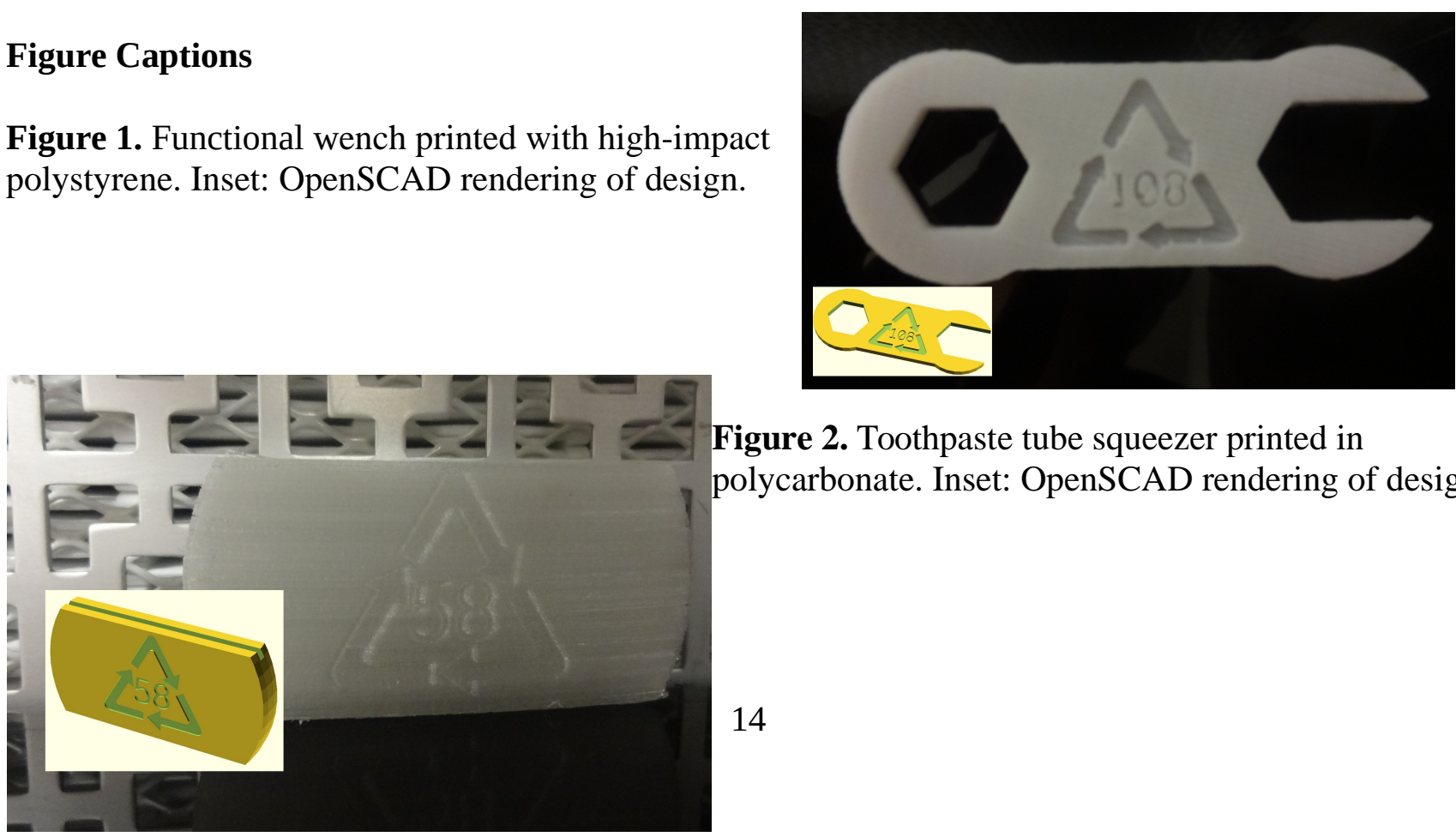

Figure 2. Toothpaste tube squeezer printed in polycarbonate. Inset: OpenSCAD rendering of design. 
E. J. Hunt, C. Zhang, N.Anzalone, and J. M. Pearce. Polymer Recycling Codes for Distributed Manufacturing with 3-D Printers, Resources, Conservation and Recycling 97, pp. 24-30 (2015). DOI: 10.1016/j.resconrec.2015.02.004

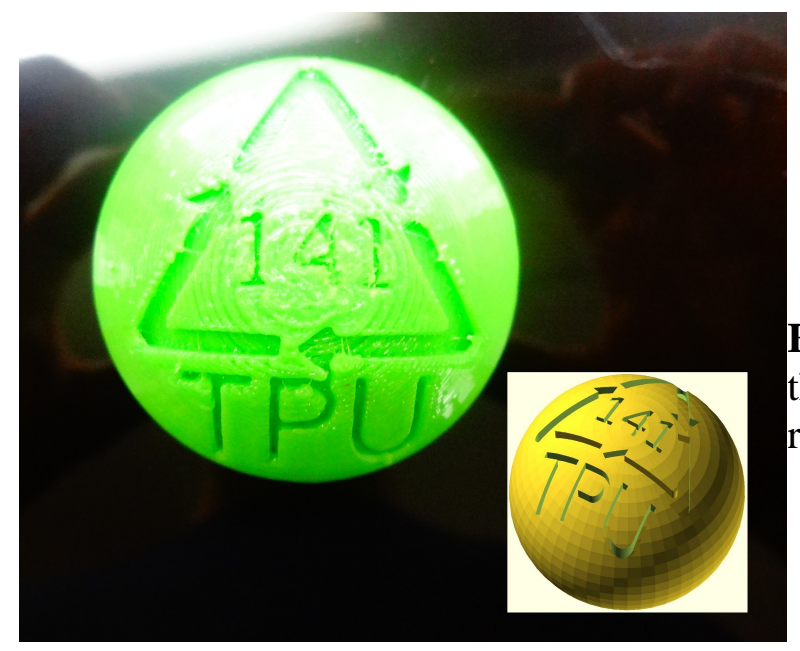

Figure 3. A toy bouncing ball was printed in thermoplastic elastomer (TPE). Inset: OpenSCAD rendering of design.

Figure 4. A drillbit handle was printed in acrylonitrile butadiene styrene (ABS). Inset: OpenSCAD rendering of design.

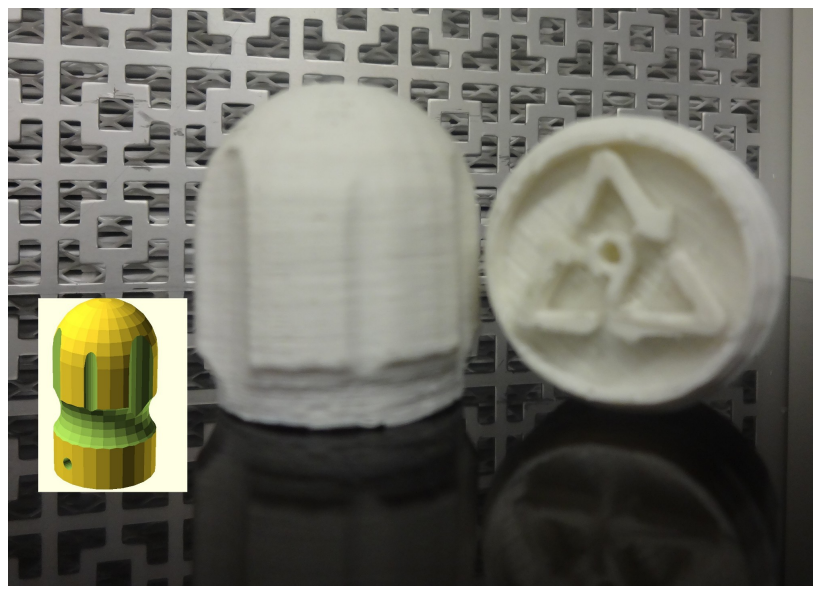


E. J. Hunt, C. Zhang, N.Anzalone, and J. M. Pearce. Polymer Recycling Codes for Distributed Manufacturing with 3-D Printers, Resources, Conservation and Recycling 97, pp. 24-30 (2015). DOI: 10.1016/j.resconrec.2015.02.004

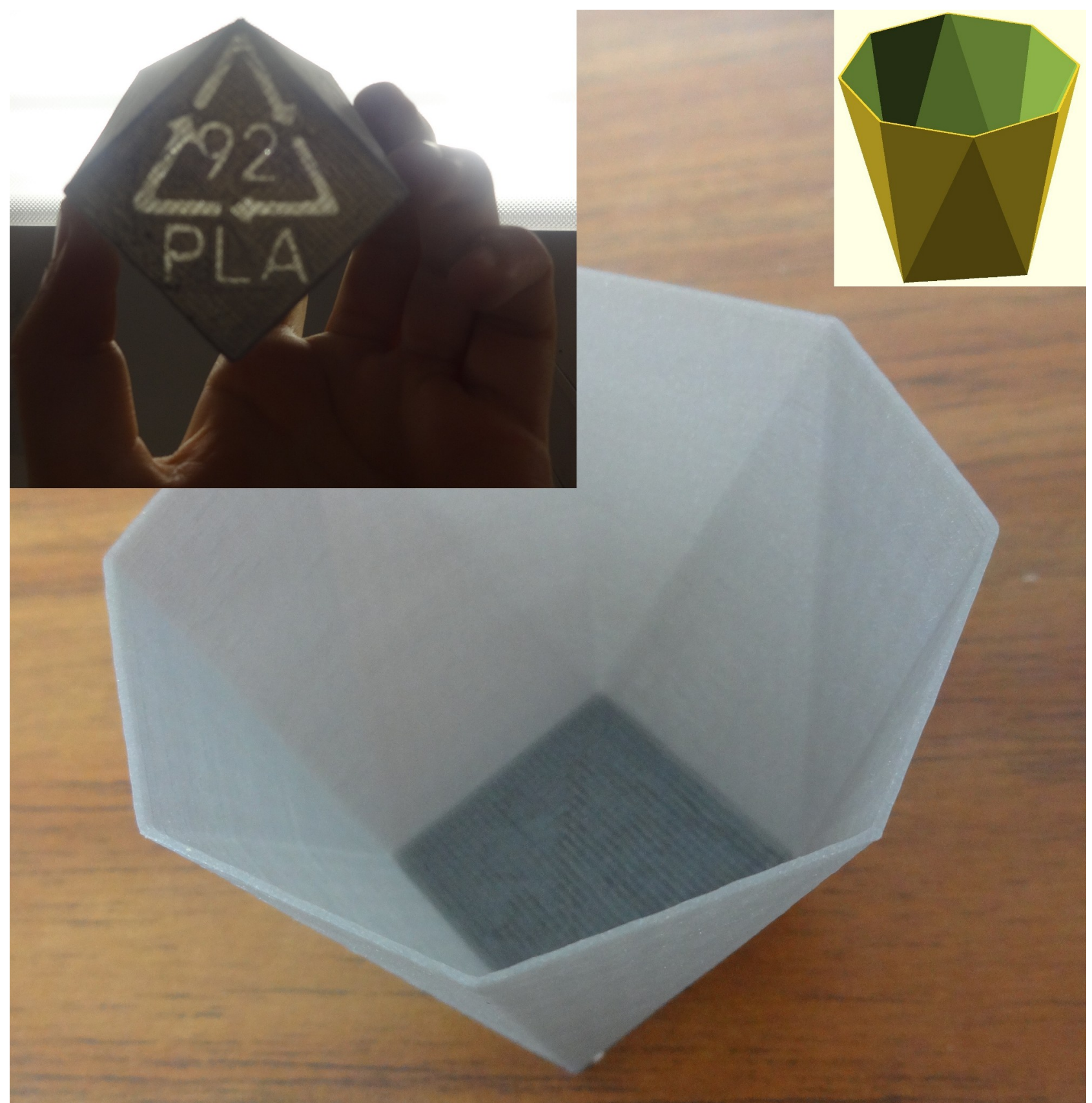

Figure 5. A pencil cup printed in polylactic acid (PLA). The left inset shows illumination of the pencil holder from the bottom. The right inset shows the OpenSCAD rendering of design.

Figure 6. An earphone holder printed in high-density polyethylene (HDPE). Inset right: OpenSCAD rendering of design. Inset left: earphones wrapped around holder.

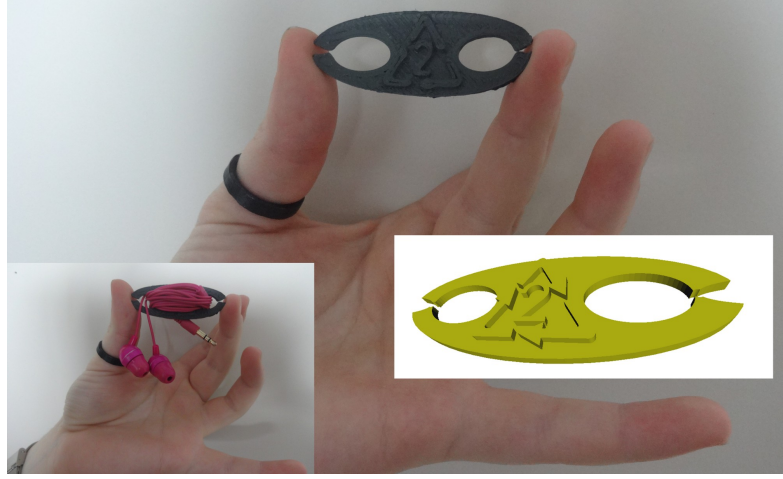


E. J. Hunt, C. Zhang, N.Anzalone, and J. M. Pearce. Polymer Recycling Codes for Distributed Manufacturing with 3-D Printers, Resources, Conservation and Recycling 97, pp. 24-30 (2015). DOI: 10.1016/j.resconrec.2015.02.004

Appendex 1. Polymer identification codes developed in China [55]. 
Appendix 1.

\begin{tabular}{|c|c|c|}
\hline Name & Abbreviation & Code \\
\hline poly(ethylene terephthalate) & PET & 1 \\
\hline polyethylene, high density & HDPE & 2 \\
\hline poly(vinyl chloride) & PVC & 3 \\
\hline polyethylene, low density & LDPE & 4 \\
\hline polypropylene & PP & 5 \\
\hline polystyrene & PS & 6 \\
\hline Acrylonitrile-butadiene plastic & $A B$ & 7 \\
\hline Acrylonitrile-butadiene-acrylate plastic & ABAK & 8 \\
\hline Acrylonitrile-butadiene-styrene plastic & ABS & 9 \\
\hline Acrylonitrile-chlorinated polyethylene-styrene & ACS & 10 \\
\hline Acrylonitrile-(ethylene-propylene-diene)-styrene plastic & AEPDS & 11 \\
\hline Acrylonitrile-methyl-methacryate plastic & AMMA & 12 \\
\hline Acrylonitrile-styrene-acrylate plastic & ASA & 13 \\
\hline cellulose acetate & $\mathrm{CA}$ & 14 \\
\hline cellulose acetate butyrate & CAB & 15 \\
\hline cellulose acetate propionate & CAP & 16 \\
\hline cellulose formaldehyde & CEF & 17 \\
\hline cellulose-formaldehyde resin & CF & 18 \\
\hline carboxymethyl cellulose & $\mathrm{CMC}$ & 19 \\
\hline cellulose nitrate & $\mathrm{CN}$ & 20 \\
\hline cycloolefin copolymer & $\mathrm{COC}$ & 21 \\
\hline cellulose propionate & $\mathrm{CP}$ & 22 \\
\hline cellulose triacetate & CTA & 23 \\
\hline Ethylene-propylene plastic & $E / P$ & 24 \\
\hline Ethylene-acrylic acid plastic & EAA & 25 \\
\hline Ethylene-butyl acrylate plastic & EBAK & 26 \\
\hline ethyl cellulose & EC & 27 \\
\hline Ethylene-ethyl acrylate plastic & EEAK & 28 \\
\hline Ethylene-methacrylic acid plastic & EMA & 29 \\
\hline epoxide; epoxy resin or plastic & EP & 30 \\
\hline Ethylene-tetrafluoroethylene plastic & ETFE & 31 \\
\hline Ethylene-vinyl acetate plastic & EVA & 32 \\
\hline Ethylene-vinyl alcohol plastic & $\mathrm{EVOH}$ & 33 \\
\hline perfluoro (ethylene-propylene) plastic & FEP & 34 \\
\hline Furan-formaldehyde resin & $\mathrm{FF}$ & 35 \\
\hline Liquid-crystal polymer & LCP & 36 \\
\hline methyl methacrylate-acrylnitrile-butadiene-styrene plastic & MABS & 37 \\
\hline methyl methacrylate-butadiene-styrene plastic & MBS & 38 \\
\hline methyl cellulose & $\mathrm{MC}$ & 39 \\
\hline Melamine-formaldahyde resin & MF & 40 \\
\hline Melamine-phenol resin & MP & 41 \\
\hline a-methylstyrene-acrylonitrile plastic & MSAN & 42 \\
\hline polyamide & PA & 43 \\
\hline poly(acrylic acid) & PAA & 44 \\
\hline polyaryletherketone & PAEK & 45 \\
\hline polyamidimide & PAI & 46 \\
\hline polyacrylate & PAK & 47 \\
\hline polyacrylonitrile & PAN & 48 \\
\hline polyarylate & PAR & 49 \\
\hline poly(aryl amide) & PARA & 50 \\
\hline polybutene & PB & 51 \\
\hline poly(butyl acrylate) & PBAK & 52 \\
\hline poly(butylene adipate/terephtalate) & PBAT & 53 \\
\hline
\end{tabular}


1,2-polybutadiene $\quad$ PBD

poly(butylene napthalate) PBN

PBN 55

polybuthylenesuccinate

PBS $\quad 56$

poly(butylene terephthalate)

PBT $\quad 57$

polycarbonate

poly(cyclohexlyene dimethylene cyclo-hexanedicar-boxylate)

$\mathrm{PC} \quad 58$

polycaprolactone

PCCE $\quad 59$

poly(cyclonhexylene dimethylene terephtahlate)

PCL $\quad 60$

polychlorotrifluoroethylene

PCT 61

poly(diallyl phthalate)

PCTFE 62

polydiclopentadiene

PDAP 63

polyester carbonate or poly(butylene succinate/carbonate)

PDCPD

polyestercarbonate

PEC

polyethylene, chlorinated

PEC 66

polyetheretherketone

PE-C

67

polyetherester

PEEK 68

polyetherimide

PEEST 69

polyetherketone

PEI $\quad 70$

PEK 71

polyethylene, linear low density

LLDPE 72

polyethylene, medium density

MDPE 73

poly(ethylene naphthalate)

PEN 74

poly(ethylene oxide)

PEOX 75

poly(ethylene succinate)

PES $\quad 76$

polyesterurethane

polyethersulfone

polyethylene, ultra high molecular weight

PESTUR 77

PESU 78

UHMWPE $\quad 79$

polyetherurethane

PEUR 80

polyethylene, very low density

VLDPE 81

Phenol-formaldehyde resin

PF 82

$\begin{array}{lll}\text { Perfluoro alkoxyl alkane resin } & \text { PFA } & 83\end{array}$

poly(glycolic acid)

PGA 84

$\begin{array}{lll}\text { polyhydroxyalanoic or polyhydroxyalkanoates } & \text { PHA } & 85\end{array}$

polyhydroxybutyric acid or polyhydroxybutyrate $\quad$ PHB 86

poly-(hydroxybutyrate-co-hydroxyvalerate)

$\begin{array}{ll}\text { PHBV } & 87\end{array}$

polyimide

polyisobutylene

$\mathrm{PI} \quad 88$

PIB 89

$\begin{array}{lll}\text { polyisocyanurate } & \text { PIR } & 90\end{array}$

polyketone

polylactic acid or poly lactide

PK 91

polymethacrylimide

PLA 92

poly (methyl methacrylate)

PMI 93

PMMA 94

Poly-N-methylmethacrylimide $\quad$ PMMI 95

poly-4-methylpenten-1 $\quad$ PMP 96

$\begin{array}{lll}\text { Poly- } \alpha \text {-methylstyrene } & \text { PMS } & 97\end{array}$

poloxymethylene; polyacetal; polyormaldehyde $\quad$ POM 98

carbon dioxide and propylene copolymer $\quad$ PPC 99

(In Chinese)

PPDO $\quad 100$

poly(phenylene ether)

PPE $\quad 101$

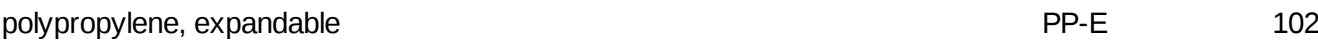

$\begin{array}{lll}\text { polypropylene, high impact } & \text { PP-HI } & 103\end{array}$

$\begin{array}{lll}\text { poly(propylene oxide) } & \text { PPOX } & 104\end{array}$

poly(phenylene sulfide) $\quad$ PPS 105

$\begin{array}{lll}\text { poly(phenylene sulfone) } & \text { PPSU } & 106\end{array}$ 
polystyrene, expandable

$\begin{array}{cc}\text { EPS } & 107 \\ \text { HIPS } & 108 \\ \text { PSU } & 109 \\ \text { PTFE } & 110 \\ \text { PTMAT } & 111 \\ \text { PTT } & 112 \\ \text { PUR } & 113 \\ \text { PVA } & 114 \\ \text { PVOH } & 115 \\ \text { PVB } & 116 \\ \text { PVC-C } & 117 \\ \text { PVC-U } & 118 \\ \text { PVDC } & 119 \\ \text { PVDF } & 120 \\ \text { PVF } & 121 \\ \text { PVFM } & 122 \\ \text { PVK } & 123 \\ \text { PVP } & 124 \\ \text { SAN } & 125 \\ \text { SB } & 126 \\ \text { SI } & 127 \\ \text { SMAH } & 128 \\ \text { SMS } & 129 \\ \text { UF } & 130 \\ \text { UP } & 131 \\ \text { VCE } & 132 \\ \text { VCEMAK } & 133 \\ \text { VCEVAC } & 134 \\ \text { VCMAK } & 135 \\ \text { VCMMA } & 136 \\ \text { VCOAK } & 137 \\ \text { VCVAC } & 138 \\ \text { VCVDC } & 139 \\ \text { VE } & 140 \\ & \end{array}$

polystyrene, high impact

polysulfone

109

poly tetrafluoroethylene

poly(tetramethylene adipate/terephtalate)

111

poly(trimethylene terephtalene)

112

polyerethane

114

115

poly(vinyl alcohol)

116

117

nated

119

poly(vinylidene chloride)

poly(vinylidene fluoride)

120

poly(vinyl fluoride)

poly(vinyl formal)

Poly-N-vinylcarbazole

Poly-N-vinylpyrrolidine

Styrene-acrylonitrile plastic

Styrene-butadiene plastic

silicone plastic

Styrene-maleic anyhydride plastic

Styrene- $\alpha$-methylstyrene plastic

Urea-formaldehyde resin

unsaturated polyester resin

vinyl chloride-ethylene plastic

vinyl chloride-ethylene-methyle-acrylate plastic

vinyl chloride-ethylene-vinyl acrylate plastic

vinyl chloride-methyl acrylate plastic

vinyl chloride-methyl methacrylate plastic

vinyl chloride-octyl acrylate plastic

vinyl chloride-vinyl acetate plastic

Vinylchloride-vynylidene chloride plastic

vinyl ester resin 